\title{
Kegelite: infrared spectroscopy and a structural hypothesis
}

\author{
R. S. W. BRAIIHWNITE \\ Chemistry Department, University of Manchester Institute of Science and Technology, Manchester M60 10D, \\ England
}

\begin{abstract}
The infrared spectrum of kegelite has been measured and is discussed. The infrared spectra of $1: 1$ molar mixtures of leadhillite with pyrophyllite or with muscovite resemble the spectrum of kegelite, the chemical formula of which is a 1:1 stoichiometric sum of those of pyrophyllite and of the leadhillite polymorphs. Kegelite is not a physical mixture of these species, but its structure may be an interlayering of phyllosilicate and leadhillite-like structures within the unit cell. The unit cell parameters of pyrophyllite-1 $T_{c}$ and the leadhillite polymorphs are compatible with each other and can be combined to give a cell with parameters close to those of the kegelite cell. A structural model for kegelite on these bases is suggested, which is also consistent with its thermal analysis. The formula of kegelite can be written as $\mathrm{Pb}_{8}\left(\mathrm{SO}_{4}\right)_{2}\left(\mathrm{CO}_{3}\right)_{4}(\mathrm{OH})_{4}(\mathrm{AlOH})_{4}\left(\mathrm{Si}_{4} \mathrm{O}_{10}\right)_{2}$.
\end{abstract}

Kl:YWORDS: kegelite, infrared spectrum, pyrophyllite, leadhillite.

\section{Introduction}

KEGELITE was first described, as a new mineral species from Tsumeb, Namibia, by Medenbach and Schmetzer (1976), and has been redefined recently by Dunn et al. (1990), who give new quantitative analyses, also thermal analysis, X-ray diffraction, infrared spectroscopic and density data, which indicate that it has the formula $\mathrm{Pb}_{8} \mathrm{Al}_{4} \mathrm{Si}_{8}\left(\mathrm{SO}_{4}\right)_{2}\left(\mathrm{CO}_{3}\right)_{4}(\mathrm{OH})_{8} \mathrm{O}_{20}$ and is monoclinic, with space group $A 2, A m$ or $A 2 / m$, and with $\mathrm{Z}=3$. The extreme flexibility of the flaky and porous material made crystallographic interpretations from single-crystal X-ray measurements difficult because of pronounced streaking of the diffraction nodes, but unit cell parameters were obtained (sec Table 2). A complete structure determination will have to await the discovery of more suitable material.

This paper presents the results of a study of the infrared spectrum of kegelite, which, considered with the data obtained by Dunn et al. (1990) and the infrared spectra of related species, suggests an interpretation of these data in terms of a structural model, the validity of which will have to await the results of more direct structural evidence.

\section{Infrared spectroscopy}

The infrared absorption spectrum of the kegelite specimen studied by Dunn et al. (1990)
(NMNH 147460), and consisting of crystals carefully selected under the binocular microscope for maximum purity, was measured over the 400 $4000 \mathrm{~cm}^{-1}$ range, using a Perkin-Elmer PE 783 precision grating infrared spectrometer. In order to minimise the effects of any moisture absorbed into $\mathrm{KBr}$ discs, the spectrum was measured in Nujol mull between $\mathrm{KBr}$ plates, and also by using a $7 \mathrm{~mm}$ pressed- $\mathrm{KBr}$ disc containing $0.7 \mathrm{mg}$ of kegelite, with a blank $\mathrm{KBr}$ disc containing the same weight of $\mathrm{KBr}$ as in the sample disc in the reference beam. This latter spectrum is reproduced in Fig. 1, and wavenumbers of absorption maxima and assignments are tabulated in Table 1. The assignments are based mainly on the known positions of absorption bands for isolated ions and bonds (Hertzberg, 1945; Nakamoto, 1978) and on comparison with published assignments for related species, as indicated. in the notes to Table 1.

In addition to the presence of the anions reported in Dunn et al. (1990), the spectrum indicates that some of the hydroxide is present in a hydrogen-bonded environment, and some in a much less hydrogen-bonded environment. The carbonate ions appear not to be appreciably distorted from their normal $D_{3 h}$ symmetry, and are therefore likely to be in sites of high symmetry. The sulphate ions are somewhat distorted from their normal $T_{d}$ symmetry. The

Mineralogical Magazine, March 1991, Vol. 55, pp. 127-134 

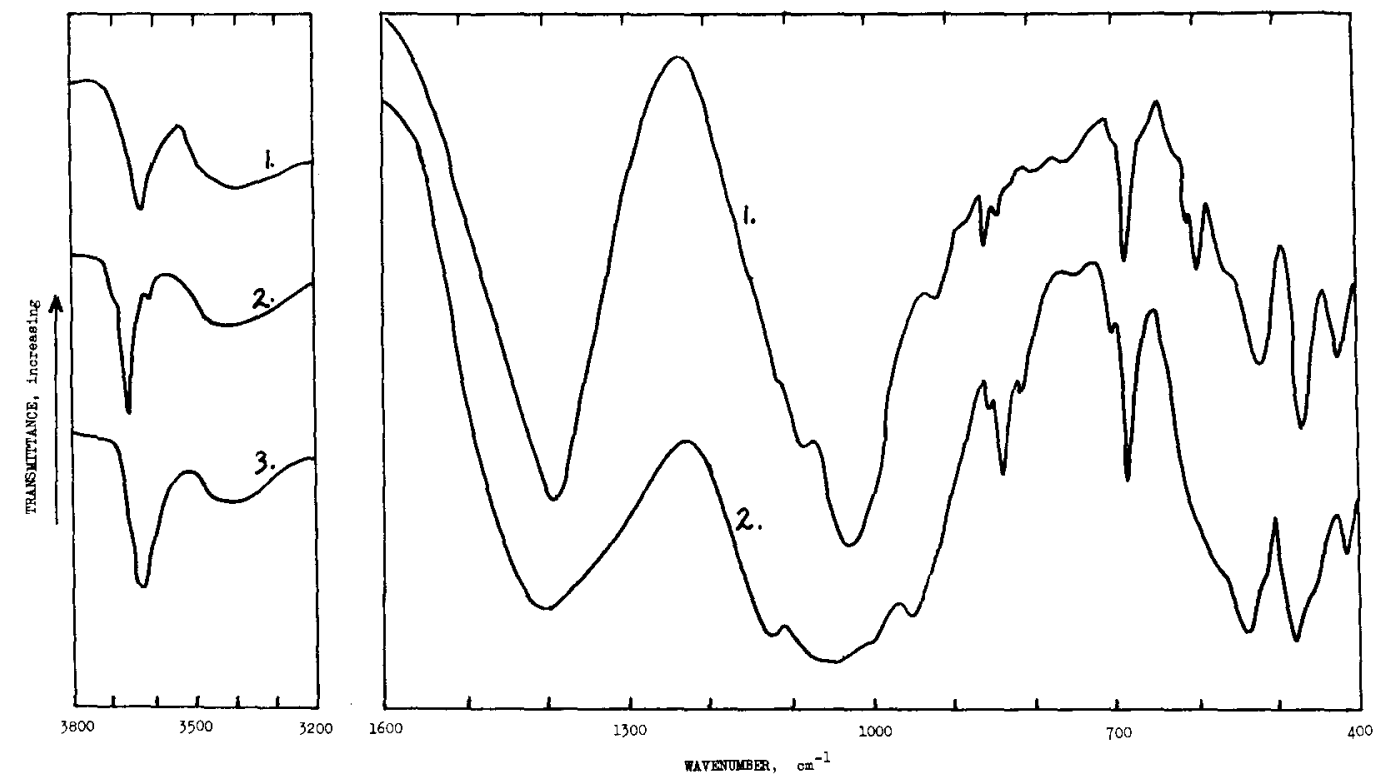

Fig. 1. Infrared spectra: 1, kegelite, off NMNH 147460;2, a 1:1 molar physical mixture of leadhillite and pyrophyllite; 3, a 1:1 molar physical mixture of lcadhillite and muscovite (O-H stretching region only).

silicate parts of the spectrum are remarkably phyllosilicate-like, as discussed below.

\section{Structural hypothesis}

The silicate parts of the infrared spectrum of kegelite are very similar to those of the phyllosilicates, in particular to those of pyrophyllite and muscovite, especially the latter. Furthermore, the $\mathrm{O}-\mathrm{H}$ stretching band at $3622 \mathrm{~cm}^{-1}$ is similar in position and profile to that which appears in the spectra of the phyllosilicates, due to the octahedrally coordinated $\mathrm{AlOH}$ hydroxides.

If $(\mathrm{AIOH})_{4}\left(\mathrm{Si}_{4} \mathrm{O}_{10}\right)_{2}$, the formula for pyrophyllite, is subtracted from that of kegelite it leaves $\mathrm{Pb}_{8}\left(\mathrm{SO}_{4}\right)_{2}\left(\mathrm{CO}_{3}\right)_{4}(\mathrm{OH})_{4}$, which is that of the leadhillite polymorphs. Stoichiometrically, then, kegelite can be regarded as pyrophyllite plus a leadhillite polymorph.

The pyrophyllite structure has long been known (Gruner, 1934, and later authors), and more recently Wardle and Brindley (1972) and Lee and Guggenheim (1981) have refined the structure of a one-layer triclinic $(1-T c)$ polymorph. The layer structure is composed of two phyllosilicate sheets linked by $(\mathrm{AlOH})_{2}$ units of paired $\mathrm{AlO}_{6}$ octahedra coordinated with oxygens of the silicate sheets.
The structures of leadhillite and its polymorphs macphersonite and susannite have been determined recently, but not published except as a poster display (Highcock et al., 1984). These structures are all based on different stackings of rather similar $\mathrm{Pb}_{8}$-containing rectangular or nearly so sub-units approximately $11.5 \times 9.1 \times$ $5.2 \AA$ in dimension (see Fig. 2 and Table 2). The infrared spectra of these leadhillite polymorphs are all very similar (Russell et al., 1984), and also have hydrogen-bonded $\mathrm{O}-\mathrm{H}$ stretching absorptions similar in profile and wavenumber to that of kegelite at $3400 \mathrm{~cm}^{-1}$.

The infrared spectra of equimolar physical mixtures of leadhillite with pyrophyllite and with muscovite were measured under similar conditions to those used for the kegelite spectrum, and are reproduced in Fig. 1. The similarity between the spectrum of kegelite and those of the mixtures is remarkable, but the differences in detail show that kegelite is not a physical mixture of pyrophyllite with a leadhillite polymorph. That it is not such a physical mixture is also indicated by its exact $1: 1$ stoichiometry, its X-ray diffraction pattern and by its behaviour on thermal analysis, discussed below. Any interlayering of these layer lattices must therefore be within the unit cell.

Is such an interlayering possible? Kegelite, 
KEGELITE

TABLE 1. Absorption maxima in the infrared Bpectrum of kegelite.

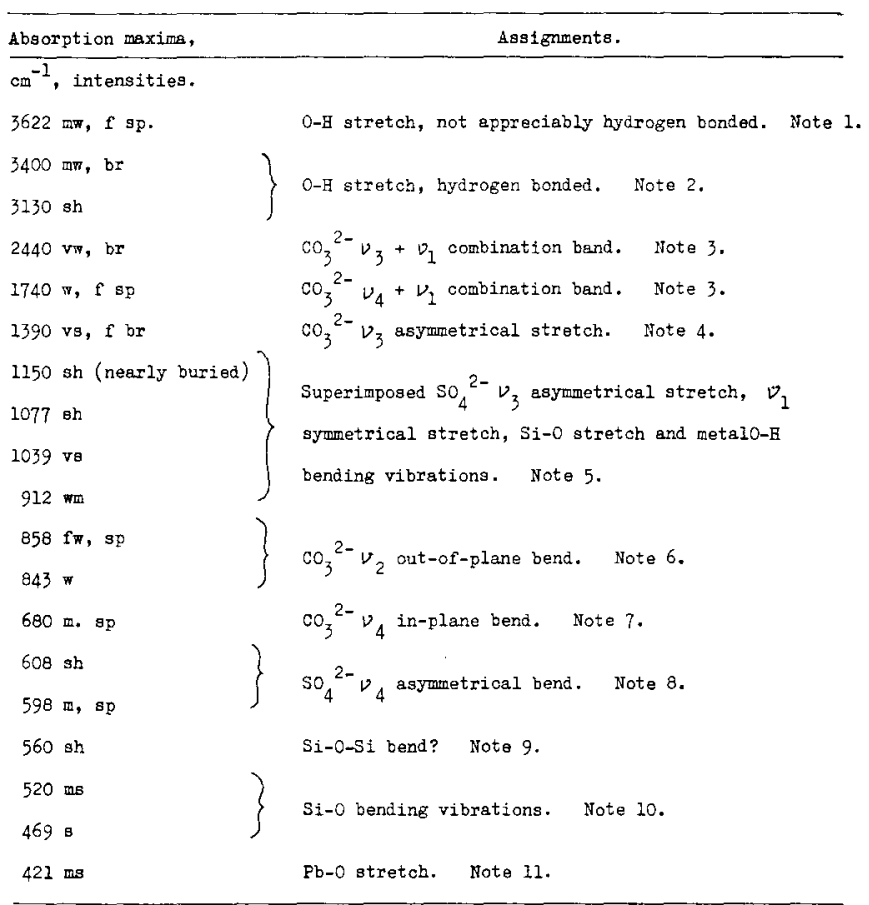

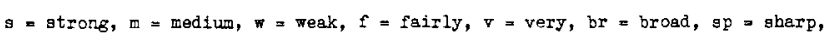

sh $=$ shoulder.

1. This closely resembles the $\mathrm{O}-\mathrm{H}$ stretching band of pyrophyllite and particularly muscovitc.

2. Leadhillite has a broad, H-bonded $\mathrm{O}-\mathrm{H}$ absorption in just this region, centred near $3400 \mathrm{~cm}^{-1}$.

3. These two weak multiphonon absorptions, common in carbonates, are combination bands as given in the table (cf. Ross and Goldsmith, 1964). Leadhillite also has these, at 2540 and $1737 \mathrm{~cm}^{-1}$ (visible on the spectrum published by Russell et al. . 1984). The positions of these bands enables the wavenumber of the $\mathrm{CO}_{2}{ }^{3-} v_{1}$ forbidden vibration to be calculated $\left(-1060 \mathrm{~cm}^{-1}\right.$, see Note 5$)$.

4. A very strong carbonate absorption, with no sign of degeneracy splitting. Thus the carbonate ion must have $D_{3, h}$ symmetry or very close to it, and is probably on a symmetrical site. In Icadhillite this is at $1409 \mathrm{~cm}^{-1}$ (Russell et al., 1984), in caledonite at $1397 \mathrm{~cm}^{-1}$ (Morgan et al. 1986).

5. A complex of overlapping absorption bands. Any site symmetry distortion degeneracy splittings are hidden, but probably not large. The $\mathrm{SO}_{4}^{2-} v_{3}$ absorption in leadhillite is split, at 1042, 1087 and $1150 \mathrm{~cm}^{-1}$ (Russell et al., 1984), and that in calcdonite is also split into three absorptions near $1000 \mathrm{~cm}^{-1}$ (Morgan et al., 1986). The weak (forbidden) $\mathrm{SO}_{4}{ }^{2-} \mathrm{v}_{1}$ symmetrical stretching vibration. revealed by anion distortion, is also buried in this complex: it is found at $964 \mathrm{~cm}^{-1}$ in the spectrum of leadhillite (Russell et al., 1984).

The Si-O stretching band in the muscovite layer lattice is at $1022 \mathrm{~cm}^{-1}$, with shoulders at 1062,990 and $935 \mathrm{~cm}^{-1}$; in pyrophyllite, the shoulders become sharp maxima at 1121 and $950 \mathrm{~cm}^{-1}$ (Farmer, 1974), doubtless due to the absence of the influence of an adjacent cation layer. In kegelite the $\mathrm{Pb}^{2+}$ cations could supply an effective cation layer, hence the morc muscovitc-likc profile. In lead sulphate orthosilicates, such as mattheddleite (Livingstone et al., 1987) and queititc. which also has $\mathrm{Si}_{2} \mathrm{O}_{7}($ Povarennykh et al. 1982), the $\mathrm{S}-\mathrm{O}$ bands around $1050 \mathrm{~cm}^{-1}$ and the Si-O absorptions around $900-950 \mathrm{~cm}^{-1}$ are well-separated and distinct.

6. At 838 and $856 \mathrm{~cm}^{-1}$ in leadhillite (Russell et al., 1984) and at 837 and $800(\mathrm{w}, \mathrm{br}) \mathrm{cm}^{-1}$ in caledonite (Morgan et al., 1986).

7. Degeneracy not split, confirming $D_{3 h}$ symmetry, or close to it. for the carbonate anion. At $679 \mathrm{~cm}^{1}$ in leadhillite (Russcll et al. 1984).

8. The shoulder at $608 \mathrm{~cm}^{-1}$ suggests distortion of the sulphate ion from $T_{i}$ symmetry. At $600 \mathrm{~cm}^{-1}$ in leadhillite (Russell et al., 1984)

9. Si-O-Si bending vibrations are found in the $55\left(-750 \mathrm{~cm}^{-1}\right.$ region (Strens, 1974).

10. Found in muscovite at 533 and $479 \mathrm{~cm}^{-1}$ and of similar strength and profilc in pyrophyllite at 541 and $483 \mathrm{~cm}^{-1}$ (Farmer, 1974).

11. Found in leadhillite at $422 \mathrm{~cm}^{-1}$ (Russell et al., 1984) and nearby in other compounds. 
pyrophyllite and the lcadhillite polymorphs tend to form platy crystals of hexagonal appearance, with pearly lustres duc to their pronounced cleavagc. A study of their lattice parameters, considering the $\mathrm{Pb}_{8}$ sub-units of the leadcontaining species, given in Table 2 , reveals an extraordinary similarity, such that a $1: 1$ combination of pyrophyllite-1 $T c$ and leadhillite polymorph layers would be quite compatible, and could fit together to produce a cell with parameters very close to those of kegelite.

Could the kegelite structure be an alternation of pyrophyllite and leadhillite-group layers, or an insertion of pyrophyllite-1 $T C$ layers into a leadhillite-group lattice? Unfortunately, these simple solutions are incompatible with the thermal analysis data. The $\mathrm{AlOH}$ hydroxyls sandwiched between the silicate sheets of pyrophyllite and the micas lose water at $650-800^{\circ} \mathrm{C}$ (Todor, 1976), whereas kegelite loses all its water by $530^{\circ} \mathrm{C}$ (Dunn et al., 1990). Leadhillite loses its water by $350^{\circ} \mathrm{C}$ (Milodowski and Morgan, 1984). The high dehydration temperature of the phyllosilicates must be connected with the mechanism of dehydration. In the phyllosilicates, the hydrox$\mathrm{yls}$ are bonded to $\mathrm{Al}$. In the $\mathrm{Al}-\mathrm{O}-\mathrm{H}$ system the $\mathrm{Al}-\mathrm{O}$ bond is very strong ( $c f$. corundum), but the $\mathrm{O}-\mathrm{H}$ bond is weak, largely because of the inductive effect of the high formal charge on the aluminium (note the well-known high acidity of the $\left[\mathrm{Al}\left(\mathrm{H}_{2} \mathrm{O}\right)_{6}\right]^{3+}$ ion and the amphotericity of $\left.\mathrm{Al}(\mathrm{OH})_{3}\right)$. The $\mathrm{Al}-\mathrm{O}-\mathrm{H}$ system can therefore easily part with a proton, but this proton cannot easily abstract a neighbouring $\mathrm{OH}^{-}$from its aluminium to produce the water:

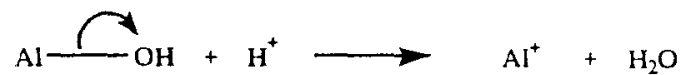

As kegelite dehydrates by $530^{\circ} \mathrm{C}$ the phyllosilicate system must be disrupted in such a way that its protons have access to easily removable $\mathrm{OH}^{-}$ ions, such as those in the leadhillite polymorph structures, but that the silicate sheets remain inviolate in order to explain the infrared spectrum. This opening up is likely to be symmetrical and therefore the pyrophyllite- $1 T C$ double layers must be peeled apart so as to expose the $(\mathrm{AlOH})_{2}$ units, with half of these attached to each silicate sheet. This separation involves breaking $\mathrm{Al}-\mathrm{O}$ bonds, so suitably placed oxygens need to be attached from another source to complete the $\mathrm{AlO}_{6}$ octahedra.

The most suitable source of such oxygen atoms are the sulphate and hydroxide ions of the leadhillite-group structures. The hydroxidecontaining layers alone cannot provide sufficient oxygens, and the carbonate groups would have to be twisted out of plane, expanding the a unit cell parameter of kegelite unacceptably and being inconsistent with the infrared data.

To derive a likely kegelite structure, the pyrophyllite half-sheets must be inserted at the correct orientation into a leadhillite-group structure along the appropriate plane ( $b c$ for leadhillite, for example) along the $\mathrm{Pb}, \mathrm{OH}$ layers adjacent to the sulphate layer, separating the lead and hydroxide units so that the $(\mathrm{AIOH})_{2}$ units can coordinate with the sulphates and hydroxides (see Fig. 2). Such an insertion could not only satisfy the $\mathrm{Al}-\mathrm{O}$ bonding requirement but would also provide the $\mathrm{Pb}^{2+}$ cation layer adjacent to the silicate sheet required to explain the closer similarity of the infrared spectrum of kegelite to that of muscovite than to that of pyrophyllite.

The postulated sequence of nine layers in the unit cell of kegelite, along the $a$ axis, would therefore be a $\mathrm{Pb}, \mathrm{CO}_{3}$ layer, followed by a $\mathrm{Pb}$, $\mathrm{OH}$ layer, a silicate sheet, an $(\mathrm{AIOH})_{2}$ layer, the sulphate and hydroxide layer and finally the other $(\mathrm{AlOH})_{2}$, silicate, $\mathrm{Pb}, \mathrm{OH}$, and $\mathrm{Pb}, \mathrm{CO}_{3}$ layers to complete the symmetry (see Fig. 2).

On the separated pyrophyllite half-sheets only two distribution patterns of alternating $(\mathrm{AlOH})_{2}$ pairs are consistent with the unit cell requirements, with alternate hydroxide-linked pairs removed either linearly or diagonally (see Fig. 3). The resulting sheets must be inserted into the structure so that the pyrophyllite $b$ axis becomes the kegelite $c$ axis, which at approximately $9 \AA$ mcans that rows of $(\mathrm{AlOH})_{2}$ pairs must run along the kegelite $b$ axis, the pairs being aligned either along $c$ (linear separation from pyrophyllite) or at $60^{\circ}$ to c (diagonal separation from pyrophyllite) (see Fig. 3).

To complete the $\mathrm{AlO}_{6}$ octahedra these patterns require four (pattern $A$ of Fig. 3) or three (pattern $B$, with a shared $O$ ) oxygen atoms to be supplied per $\mathrm{Pb}_{x}$ sub-unit. The sulphates alone contain sufficient oxygens for these, but the stereochemistry does not allow more than one oxygen per sulphate ion to attach to each $(\mathrm{AlOH})_{2}$ pair (two oxygens attached to one sulphur can bridge within one sheet in various patterns, but the tetrahedral configuration of sulphate does not then allow any suitable oxygen linkage patterns with the other sheet). The stereochemical requirements are considerably relaxed if the sulphates bridge with one oxygen to each shect, and the extra oxygens are supplied by the neighbouring hydroxide groups. Pattern A of Fig. 3 would require all the hydroxides to lie within the sulphate layer to coordinate with the aluminium, but pattern $B$ would only require the inner set of 

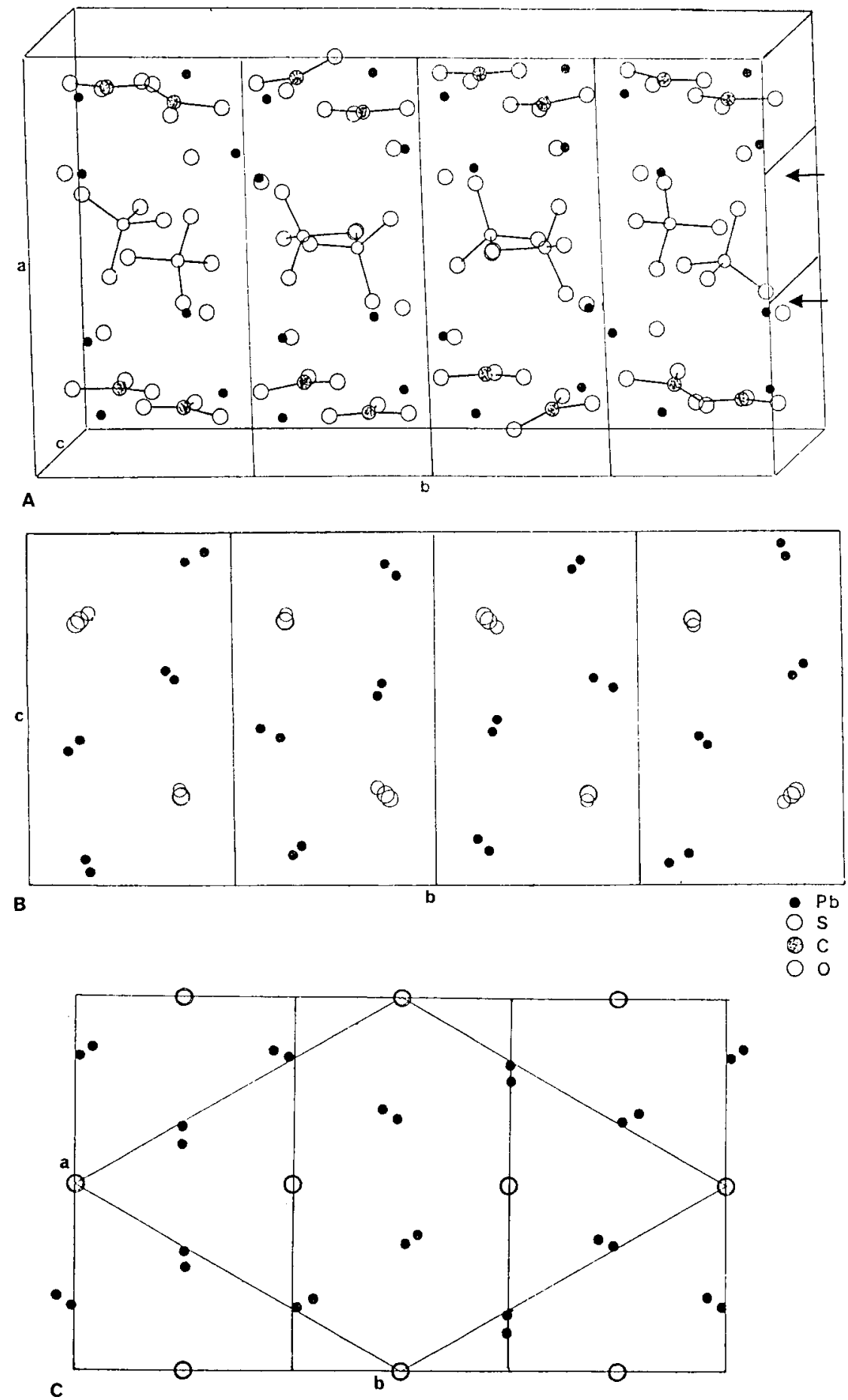

FiG. 2. Unit cells of leadhillite (A, B) and of susannite (C, $a b$ plane only) (from Highcock et al. . 1984), divided into $\mathrm{Pb}_{8}$ sub-units. The arrows on $\mathrm{A}$ indicate the likely positions of the phyllosilicate layers in kegelite. The axial lettering for kegelite is the same as that for leadhillite. 
TABLE 2 Comparison of lattice paraneters of sultably oriented unit cells or $\mathrm{Pb}_{8}$ sub-units of the leadhillite polymorphs, pyrophyllite and kegelite.

\begin{tabular}{|c|c|c|c|c|}
\hline Species & Comparative uni & t cell dimensions, $f$ & & References \\
\hline Leadhillite & a. 11.58 & $b / 4,5.20(b, 20.81)$ & $c, 9.11$ & Highcock et al., 1984. \\
\hline Sugannite & c, 11.57 & $b / 3,5.23(b, 15.70)$ & a. 9.07 & Higheock et al., 1984. \\
\hline Nacphersonite & $\mathrm{b} / 2,11.55(\mathrm{~b}, 23.10)$ & $c / 2,5.18(0,10.37)$ & a, 9.23 & Higheock et al., 1984. \\
\hline Pyrophylite- $\underline{19}$ & $c, 9.35$ & $a, 5.16$ & $\mathrm{~b}, 8.96$ & $\begin{array}{l}\text { Wardle and Brindley, } 1972, \\
\text { Lee and Guggenheim, } 1981 .\end{array}$ \\
\hline Kegelite & $\begin{array}{l}\text { a, } 21.04 \\
(=9.35+11.69)\end{array}$ & $b / 3,5.18(b, 15.55)$ & $c, 8.99$ & Dunn et al., 1990. \\
\hline
\end{tabular}

hydroxides to coordinate with the Al, and would therefore be preferred.

The cmpirical formula of kegelite has all multiplicities divisible by 4 except that of sulphur, divisible by 2 . The space groups $A 2$ and $A m$ proposed by Dunn et al. (1990) require all sites to be in multiples of 4 unless the sulphur is on a 2 fold axis or a mirror plane, when multiples of 2

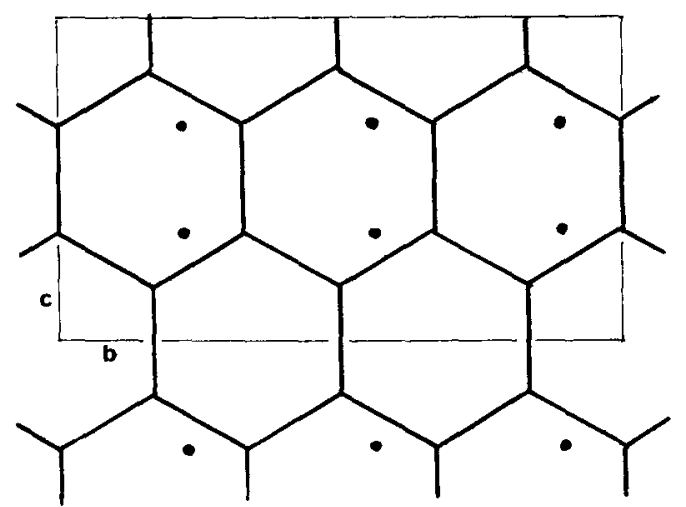

A,
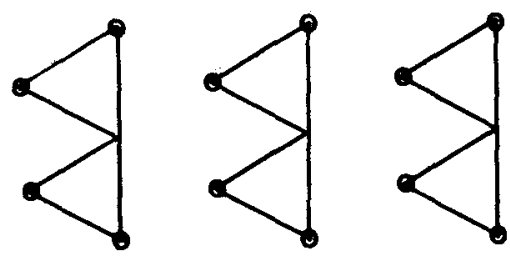

$\mathbf{A}_{2}$ are allowed. $A 2 / m$ requires multiples of 8 and so seems less plausible unless considerable disorder is present. In the proposed model the sulphurs occupy midline positions, bridging probably symmetrically, and so may well be on a mirror plane. If not, the structure could still be reconciled with the first two space groups if the sulphurs occupy half of four available sites. Four sulphates per

FIG. 3. $A_{1}, B_{1}$. Possible arrangements of pyrophyllitc-1TC half-layers within the kegelite unit cell. A, linear alignment of $(\mathrm{AlOH})_{2}$ units. $\mathrm{B}$. diagonal alignment of $(\mathrm{AlOH})_{2}$ units. $\mathrm{A}_{2}, \mathrm{~B}_{2}$. Corresponding patterns of $\mathrm{AlO}_{6}$ octahedra in the $b c$ plane of kegelite, showing only the faces unattached to the silicate sheet and the $\mathrm{O}$ atoms which have to be supplied from sulphate and hydroxide (marked o). The intersections between pairs of triangles are already occupied by $\mathrm{OH}$ groups of $(\mathrm{AlOH})_{2}$. 
formula unit would not fit the analyses, would disturb the charge balance and would be hopelessly overcrowded because of the oxygen atoms.

With regard to the thermal analyses, the multiplicity of hydroxide environments broadens the water-loss temperature range compared with that of leadhillite. Kegelite loses $\mathrm{SO}_{2}$ from sulphate at a somewhat lower temperature (Dunn et al., 1990) than leadhillite does (Milodowski and Morgan, 1984). Aluminium sulphates lose $\mathrm{SO}_{2}$ at a similarly lower temperature than lead sulphates do (Todor, 1976), which is consistent with the juxtaposition of $\mathrm{Al}$ next to sulphates in kegelite.

The infrared spectrum of the model would be expected to approximate to a superimposition of that of a leadhillite group mineral (the three polymorphs have rather similar infrared spectra) with that of a layer hydroxyaluminosilicate, as observed. Overlap of sulphate and silicate absorptions confuses assessment of sulphate coordination.

If the $c$ parameter of pyrophyllite- $1 T c$ is added to the appropriate parameters of the leadhillite polymorphs, a value close to the $a$ parameter of kegelite is obtained, the other appropriate parameters of all these minerals being closely comparable with each other (Table 2). The small differences between the parameters can be accommodated by quite small shifts in the positions of the ions in the leadhillite-group structures, which also affect the symmetry within the $\mathrm{Pb}_{8}$ sub-units and hence the repeat unit of their stacking. A stacking of alternating sub-units would forbid $Z=3$, but would allow $Z=6$ and a doubled $b$ parameter for example. The $b$ values for pyrophyllite-1 $1 c$ and kegelite are particularly close, as the fixed pyrophyllite sheet would control this value, the ionic leadhillite group structures having more flexibility in ion positions.

\section{Conclusion}

The available data suggests that the structure of kegelite is likely to be a layer-lattice one, composed of covalent phyllosilicate sheets interlayered within the unit cell within an ionic structure resembling that of the leadhillite polymorphs (particularly susannite, as $Z=3$ ), and that its formula should be written as $\mathrm{Pb}_{8}\left(\mathrm{SO}_{4}\right)_{2}\left(\mathrm{CO}_{3}\right)_{4}(\mathrm{OH})_{4}(\mathrm{AlOH})_{4}\left(\mathrm{Si}_{4} \mathrm{O}_{10}\right)_{2}$. A structural model is proposed which is consistent with the chemical and thermal analyses, physical properties, infrared spectra and unit cell parameters of kegelite. This structure may be compared with the related but simpler structure proposed for surite (Hayase et al., 1978), in which the phyllosilicate unit is not split, and sulphate and hydroxide are absent from the ionic layers.

\section{Acknowledgements}

Thanks are due to the Department of Mineral Sciences, National Muscum of Natural History. Smithsonian Institution for the sample of kcgelite, to $\mathrm{Mr}$ Ken Walkling of the Chemistry Department. UMIST, for running infrared speetra, and to Dr B. Beagley and Prof. D. W. J. Cruickshank FRS, of the same department, for helpful discussions. The author is particularly grateful to the late Dr P. H. Spriggs for calculations and most helpful discussions, and to Mary Vickers of B.P. Research Centre. Sunbury-on-Thames for permission to use her diagrams to produce Fig. 2.

\section{References}

Dunn, P. J., Braithwaite, R. S. W., Roberts, A. C., and Ramik. R. A. (1990) Kegclite from Tsumeb. Namibia: a redefinition. Am. Mineral. , 75, 702-4.

Farmer, V. C. (1974) In The infrared spectra of minerals. Mincralogical Socicty. London, 331-63.

Gruner, J. W. (1934) The crystal structures of tale and pyrophyllite. Zeits. Kristallogr., 55, 412-19.

Hayase, K., Dristas, J. A., Tsutsumi, S., Otsuka, R., Tanabc, S., Sudu, T., and Nishiyama, T. (1978) Surite, a new Pb-rich layer silicate mineral. Am. Mineral. 63, 1175-81.

Hertzberg, G. (1945) Molecular spectra and molecular structure. 2. Infrared and Raman spectra of poly. atomic molecules. Van Nostrand. New York.

Highcock, R. M., Smith, G. W., and Vickers, M. E. (1984) On the structural relationship between two polymorphs of $\mathrm{Pb}_{4} \mathrm{SO}_{4}\left(\mathrm{CO}_{3}\right)_{2}(\mathrm{OH})_{2}$, also Susannite. Acta Crystallogr., A40, supplement, p. C-249. Abstract 084-17. Poster display, International Union of Crystallography meeting. Hamburg.

Lee, J. H. and Guggenheim. S. (1981) Single erystal X-ray refinement of pyrophyllite-1Tc. Am. Mineral., 66. 350-7.

Livingstone, A., Ryback, G., Fejer, E. E., and Stanley, C. J. (1987) Mattheddleite, a new mineral of the apatite group from Leadhills, Strathclyde region, Scotland. Scott. J. Geol., 23, 1-8.

Medenbach, O. and Schmetzer, K. (1976) Kegelite-a new lead silicate from Tsumeb. Neues Jahrb. Mineral, Mh., 110-13.

Milodowski, A. E. and Morgan, D. J. (1984) Thermal reactions of leadhillite, $\mathrm{Pb}_{4} \mathrm{SO}_{4}\left(\mathrm{CO}_{3}\right)_{2}(\mathrm{OH})_{2}$. Clay Mincrals, 19, 825-41.

Morgan, D. J., Warne, S. St. J., Warrington, S. B., and Nancarrow, P. H. A. (1986) Thermal decomposition reactions of calcdonite and their products. Mineral. Mag., 50, 521-6.

Nakamoto, K. (1978) Infrared and Raman spectra of inorganic and coordination compounds. 3rd ed. John Wiley and Sons. New York.

Povarennykh, A. S. Keller, P., and Kristiansen, R. (1982) Infrared absorption spectra of swedenborgite and queitite. Can. Mineral., 20.601-3. 
Ross, S. D. and Goldsmith, J. (1964) Factors affecting the infrared spectra of planar anions with $D_{3 h}$ symmetry-I. Carbonates of the main group and first row transition elements. Spectrochim. Acta, 20, $781-84$.

Russell, J. D., Fraser, A. R., and Livingstone, A (1984) The infrared absorption spectra of the three polymorphs of $\mathrm{Pb}_{4} \mathrm{SO}_{4}\left(\mathrm{CO}_{3}\right)_{2}(\mathrm{OH})_{2}$ (leadhillite, susannite and macphersonite). Mineral. Mag., 48. 295-7.
Strens, R. J. G. (1974) In The infrared spectra of minerals (Farmer, V. C., ed.). Mineralogical Society, London, 305-30.

Todor, D. N. (1976) Thermal analysis of minerals. Abacus Press, Kent, England.

Wardle, R. and Brindley, G. W. (1972) The crystal structures of pyrophyllite-1 $T_{C}$, and of its dehydroxylate. Am. Mineral., 57, 732-50

[Manuscript received 11 March 1990] 